\title{
Visualizing Low Contrast Compositional Microstructures with SDD-EDS X-ray Spectrum Imaging in the Scanning Electron Microscope
}

\author{
Dale E. Newbury
}

National Institute of Standards and Technology, Gaithersburg, MD 20899-8370

The extraordinary x-ray throughput that can be achieved with the silicon drift detector energy dispersive spectrometer (SDD-EDS), e.g., an output count rate (OCR) exceeding $1 \mathrm{MHz}$ with a spectral resolution of $145 \mathrm{eV}$ (at $\mathrm{MnK} \alpha$ ) and with excellent peak stability (width and position) over the full range of input count rate, opens new possibilities for elemental mapping [1]. Elemental mapping has always been a popular mode of operation for scanning electron microscope-EDS evaluation of microstructures, but the limited OCR of the $\mathrm{Si}(\mathrm{Li})$-EDS, even with a short time constant and resolution poorer than $160 \mathrm{eV}$, results in a severe time penalty when mapping minor and trace constituents or revealing small changes in concentration [2]. X-ray elemental imaging for such applications has previously been restricted to wavelength dispersive x-ray spectrometry (WDS), which still retains special advantages over EDS such as higher peak-to-background and no increase in counting deadtime due to high abundance matrix constituents. However, WDS is inevitably limited to mapping only the elements chosen, whereas EDS mapping in the x-ray spectrum imaging (XSI) mode of operation effectively captures all possible elemental information within the restrictions imposed by the primary dose and the EDS performance. Unexpected constituents can be identified in the XSI database with a variety of software tools and mapped without the need to make additional measurements [3, 4]. With SDD-EDS XSI, mapping of minor and trace constituents and low concentration contrast can be achieved with modest time expenditure. Figure 1 shows an example of imaging a complex $\mathrm{Zr}-\mathrm{Ni}$ alloy with $\mathrm{Ti}, \mathrm{V}, \mathrm{Mn}$, and Co present as minor constituents. The XSI was prepared with an SDD time constant that provided resolution of $127.5 \mathrm{eV}$, at an OCR of $300 \mathrm{kHz}$, and a pixel density of $512 \times 384$ with a dwell of $8192 \mu$ s for a mapping time of 27 minutes. The concentration ranges depicted in the gray scale images (background and interference corrected) represent minor $\mathrm{V}$ (0.013 to 0.098 mass fraction) and $\mathrm{Cr}$ (0.006 to 0.101$)$, and major $\mathrm{Ni}$ (0.34 to 0.42). Sufficient $\mathrm{x}$-ray counts were recorded to depict subtle concentration features with high spatial resolution. Figure 2 demonstrates SDD-EDS XSI imaging of low contrast of major constituents. Aluminum wire in a steel electrical junction box can fail through a high temperature process that forms a complex interaction zone containing Al-Fe intermetallic compounds. The XSI maps (512x384, $4096 \mu$ s dwell; $1.1 \mathrm{MHz}$ at $145 \mathrm{eV}$ resolution) in Figure 2 show the concentration contrast between $\mathrm{Al}_{3} \mathrm{Fe}$ and $\mathrm{Al}_{5} \mathrm{Fe}_{2}$. The concentration contrast is $7.6 \%$ in the $\mathrm{Al}$ map and $9.9 \%$ in the Fe map.

References

[1] D. Newbury, Spectroscopy, 24 (2009) 32-43.

[2] J. Goldstein et al., Scanning Electron Microscopy and X-ray Microanalysis, $3^{\text {rd }}$ ed. (Springer, New York, 2003) 485.

[3] D. Bright, Lispix, available free at http://www.nist.gov/lispix/doc/contents.htm.

[4] P. Kotula et al, Micros. Microanal., 9 (2003) 1. 

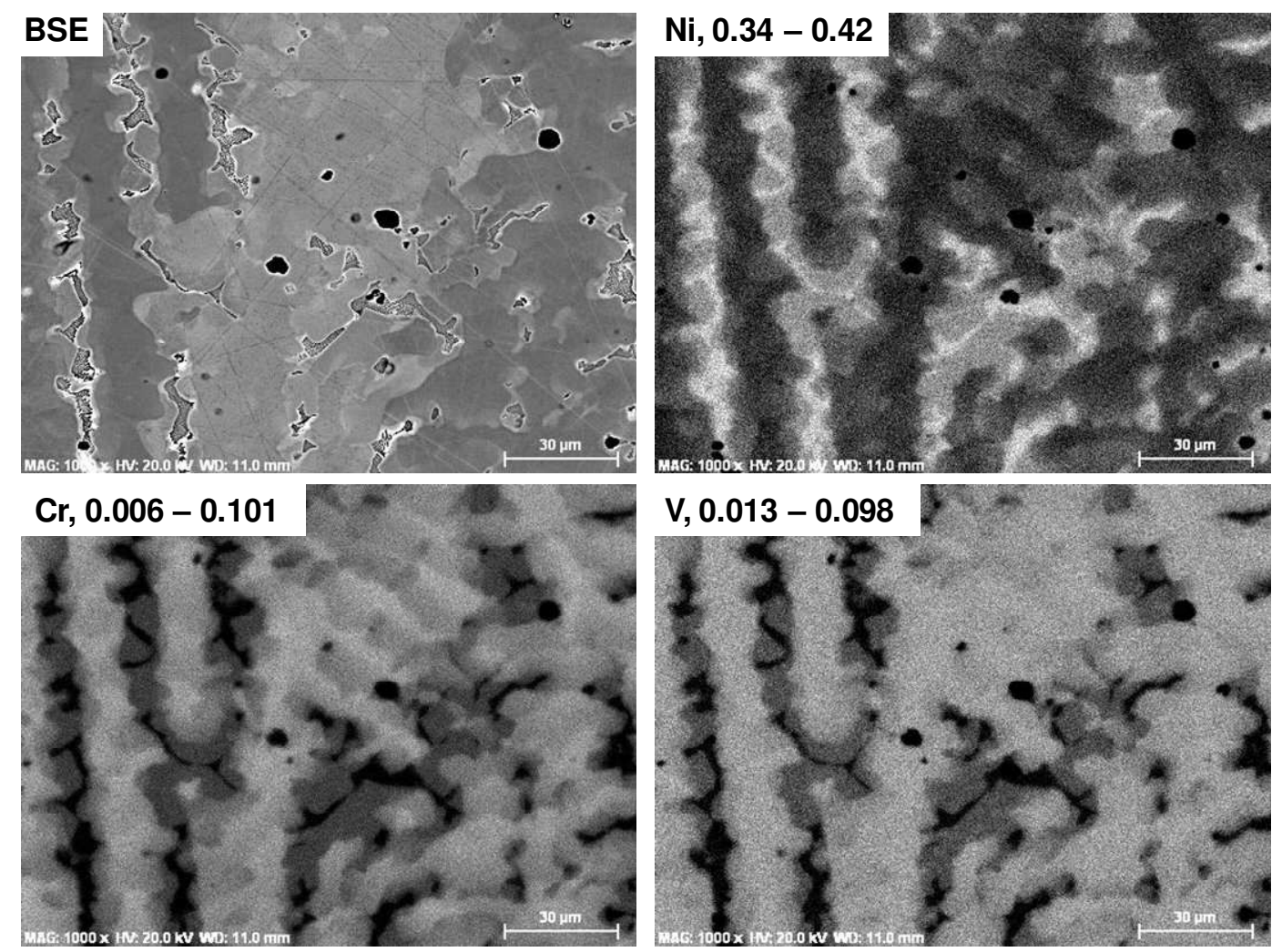

FIG1 Zr-Ni alloy with minor Ti, V, Cr, Mn, and Co. XSI: 512x384 pixels (8192 $\mu \mathrm{s})$
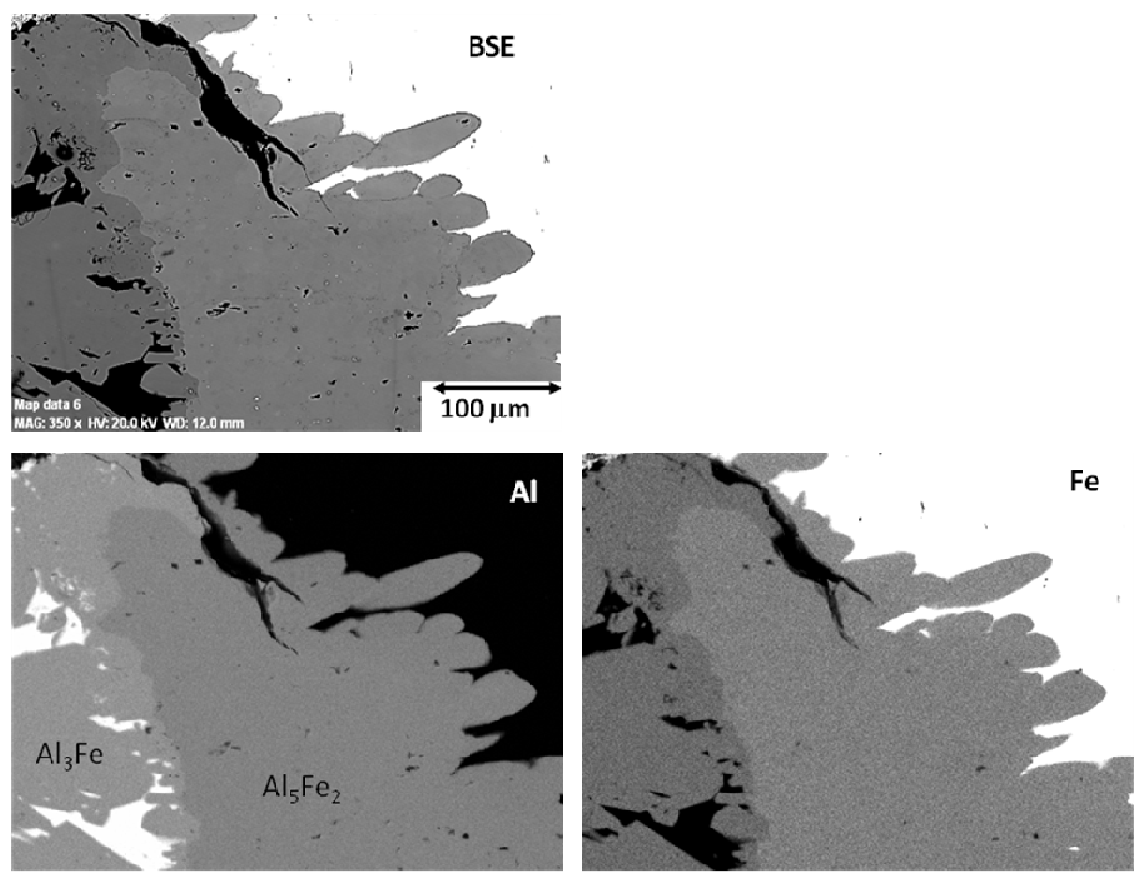

FIG. 2. Al wire - steel screw interface after thermal failure: 512x384 (4096 $\mu$ s). In the Al map, the phase contrast is $7.6 \%$, while in the Fe map the contrast is $9.9 \%$. 